\title{
Mechanical ventilation-associated pneumothorax presenting with paroxysmal supraventricular tachycardia in patients with acute respiratory failure
}

\author{
Jeong Ho Eom', Myung Goo Lee ${ }^{1}$, Chang Youl Lee', Kyong Min Kwak', Won Jae Shin', \\ Jung Wook Lee ${ }^{1}$, Seong Hoon $\mathrm{Kim}^{1}$, Sang Hyeon Choi ${ }^{1}$, So Young Park ${ }^{2}$ \\ ${ }^{I}$ Division of Pulmonary, Allergy and Critical Care Medicine, Department of Internal Medicine, Chuncheon Sacred Heart Hospital, \\ Hallym University College of Medicine, Chuncheon; ${ }^{2}$ Department of Internal Medicine, Gangdong Sacred Heart Hospital, \\ Hallym University College of Medicine, Seoul, Korea
}

The prevalence of pneumothorax cases among Intensive Care Unit patients who require mechanical ventilation ranges from $4 \%-15 \%$. A pneumothorax remains one of the most serious complications of positive pressure ventilation. It can be diagnosed in a critically ill patient through a physical examination or radiographic studies that include chest radiographs, ultrasonography, or computed tomography scanning. However, in a critically ill patient, the diagnosis of a pneumothorax is often complicated by other diseases and by difficulties in imaging sick and unconscious patients. Although electrocardiogram changes associated with a pneumothorax have been described for many years, there has been no report of such among patients who require mechanical ventilation. In this paper, we report 2 cases of a spontaneous pneumothorax with paroxysmal supraventricular tachycardia in patients who required invasive mechanical ventilation due to acute respiratory failure.

Keywords: Pneumothorax; Supraventricular tachycardia; Artificial respiration

\section{INTRODUCTION}

A pneumothorax in a critically ill patient who requires mechanical ventilation remains a serious condition [1-3]. It should be considered a medical emergency requiring a high index of suspicion, prompt recognition, and intervention. Patients with a pneumothorax commonly complain of chest pain and dyspnea that mimic myocardial infarction (MI), or tachycardia and hypotension.

Before performing a chest X-ray, an electrocardiogram (ECG) reading is often ordered first for evaluation of patients with chest pain and dyspnea. Although ECG is not at all considered a primary test for a pneumothorax, it can be a

Received: June 8, 2014, Revised: August 13, 2014, Accepted: August 20, 2014

Corresponding Author: So Young Park, Department of Internal Medicine, Kangdong Sacred Heart Hospital, Hallym University College of Medicine, 150 Seongan-ro, Gangdong-gu, Seoul 05355, Korea

Tel: +82-2-2224-2977, Fax: +82-2-2224-2213

E-mail: p0702@chol.net useful tool for recognizing a pneumothorax when the diagnosis is uncertain from the patient's history and physical examination.

In this paper, we report on 2 cases of a spontaneous pneumothorax that was presented with paroxysmal supraventricular tachycardia (PSVT) by patients who required invasive mechanical ventilation due to acute respiratory failure.

\section{CASES}

\section{CASE 1}

A 74-year-old man who was $155 \mathrm{~cm}$ tall and weighed 42.5 $\mathrm{kg}$ was admitted to the authors' hospital due to pneumonia (Fig. 1). He was intubated and assisted ventilation was administered in the Intensive Care Unit (ICU). The ventilator settings were as follows: pressure control mode rate, 16/min; $\mathrm{FiO}_{2}$, 0.35 ; positive end-expiratory pressure (PEEP), $0 \mathrm{cmH}_{2} \mathrm{O}$; and above PEEP, $16 \mathrm{cmH}_{2} \mathrm{O}$. His initial ECG was sinus rhythm with $\mathrm{T}$ wave inversion (Fig. 2A). Echocardiography showed 
a left ventricular hypertrophy and right ventricular hypertrophy. Normal left ventricle and right ventricle systolic function. Mild tricuspid regurgitation with normal pulmonary artery pressure. On day +20 after intubation, blood pressure (BP) suddenly dropped to $72 / 45 \mathrm{mmHg}$, with a heart rate $(\mathrm{HR})$ of 170 beats/min. The laboratory findings were as follows: creatine kinase-MB (CK-MB), $8.49 \mathrm{ng} / \mathrm{mL}$; troponin-I, 1.291 $\mathrm{ng} / \mathrm{mL}$; and d-dimer, 2,852 ng/mL. A arterial blood gas analysis (ABGA) with mechanical ventilation showed a $\mathrm{pH}$ of 7.455; $\mathrm{PaO}_{2}, 87.1 \mathrm{mmHg} ; \mathrm{PaCO}_{2}, 27.6 \mathrm{mmHg}$; and $\mathrm{HCO}_{3}^{-}$, $19.6 \mathrm{mEq} / \mathrm{L}$, with $97.3 \%$ oxygen saturation. ECG was PSVT at 177 beats/min (Fig. 2B). Auscultation of his lungs revealed diminished breath sounds in the left chest. The initial chest X-ray showed a left-sided pneumothorax (Fig. 3A). A computed tomography (CT) scan of the chest was ordered to confirm the diagnosis of a pneumothorax. The CT showed no pulmonary embolism. The chest CT axial images confirmed a large left pneumothorax (Fig. 3B). The patient underwent

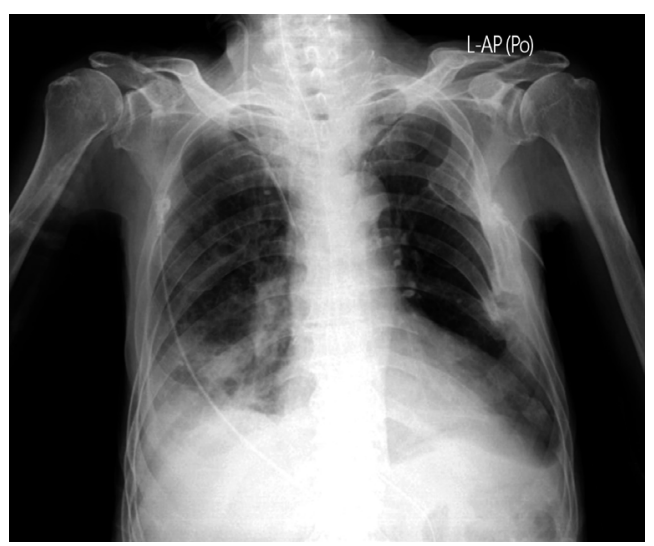

Fig. 1. Initial X-ray showing consolidation in the right lower lung field and old fractures in the left ribs.

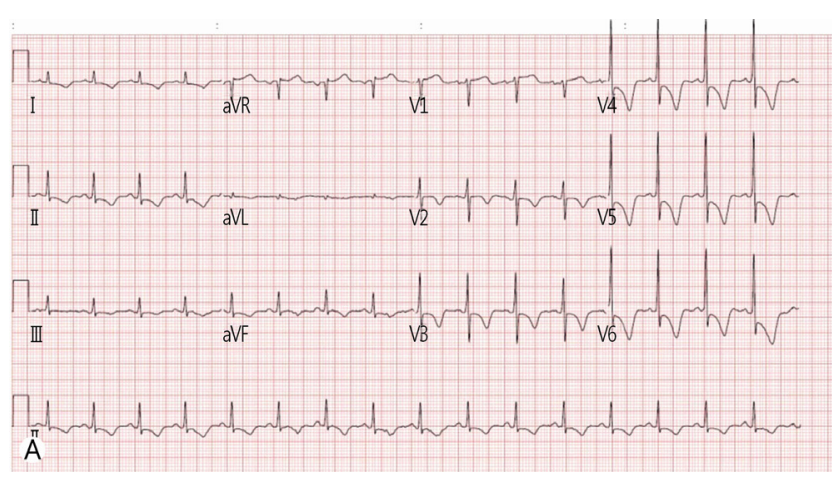

emergent chest tube placement. After chest tube placement, BP increased to $130 / 87 \mathrm{mmHg}$, with an $\mathrm{HR}$ of 83 beats $/ \mathrm{min}$. His repeat cardiac markers were CK-MB, $7.41 \mathrm{ng} / \mathrm{mL}$ and troponin-I, $1.399 \mathrm{ng} / \mathrm{mL}$; and ABGAs showed a $\mathrm{pH}$ of 7.414; $\mathrm{Pa} \mathrm{O}_{2}, 88.5 \mathrm{mmHg} ; \mathrm{PaCO}_{2}, 33.6 \mathrm{mmHg}$; and $\mathrm{HCO}_{3}, 21.7$ $\mathrm{mEq} / \mathrm{L}$ with $97.0 \%$ oxygen saturation. A repeat chest X-ray showed resolution of the left penumothorax (Fig. 3C), and a repeat ECG demonstrated conversion of the PSVT to a normal sinus rhythm (Fig. 4). A repeat echocardiography showed no interval change. The patient was free of complications throughout the rest of his hospitalization, and his chest tube was successfully removed after a few days.

\section{CASE 2}

A 53-year-old woman presented at our institution's emergency department due to sudden onset of dyspnea. Her medical history included a destroyed lung by tuberculous. She was admitted with pneumonia (Fig. 5), and intubated and assisted ventilation was administered in the ICU. The ventilator was set at the pressure support mode at a $\mathrm{FiO}_{2}$ of 0.55 , a PEEP
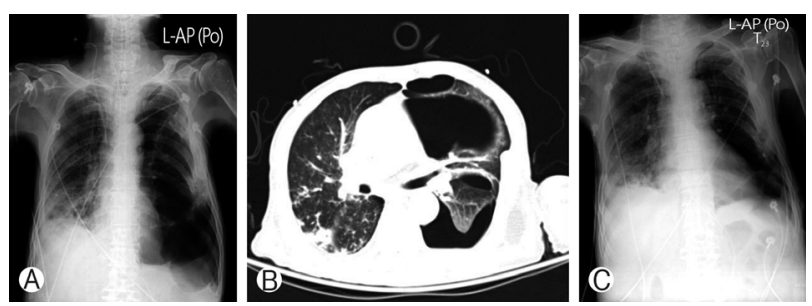

Fig. 3. (A) Chest X-ray showing a left-sided pneumothorax. (B) Chest computed tomography axial images showing a large left pneumothorax. (C) Chest X-ray after chest tube placement showing resolution of the left-sided pneumothorax.

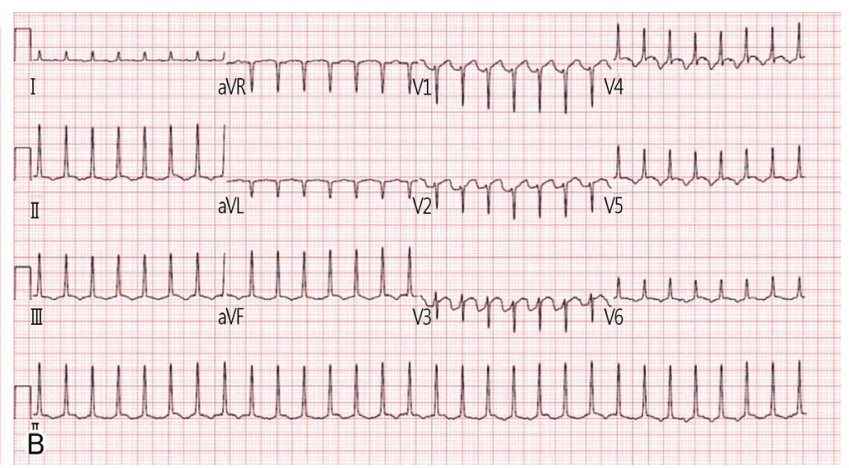

Fig. 2. (A) ECG showing the patient's sinus rhythm with T wave inversion. (B) ECG demonstrating PSVT. ECG, electrocardiogram; PSVT, paroxysmal supraventricular tachycardia. 
of $3 \mathrm{cmH}_{2} \mathrm{O}$, and an above PEEP of $25 \mathrm{cmH}_{2} \mathrm{O}$. Her initial ECG showed a normal sinus rhythm (Fig. 6A). Echocardiography showed a right ventricular enlargement with right ventricle dysfunction and right ventricular systolic pressure was $68 \mathrm{mmHg}$. BP suddenly dropped to $87 / 51 \mathrm{mmHg}$, with an $\mathrm{HR}$ of 207 beats/min. Laboratory findings were as follows: CK-MB, $10.3 \mathrm{ng} / \mathrm{mL}$; troponin-I, $0.019 \mathrm{ng} / \mathrm{mL}$; and d-dimer, $960 \mathrm{ng} / \mathrm{mL}$. ABGA with mechanical ventilation revealed a $\mathrm{pH}$ of 6.92; $\mathrm{PaO}_{2}, 44.6 \mathrm{mmHg} ; \mathrm{PaCO}_{2}, 167 \mathrm{mmHg}$; and $\mathrm{HCO}_{3}^{-}$, $34.6 \mathrm{mEq} / \mathrm{L}$ with $46.5 \%$ oxygen saturation. ECG was PSVT at 207 beats/min (Fig. 6B). Adenosine (6 mg) was administrated and sinus rhythm was sucessfully converted. Chest X-ray showed a right-sided pneumothorax (Fig. 7A). She underwent emergent chest tube placement were undergone and pneumothoracic was resolved (Fig. 7B). After insertion of the chest tube, her BP increased to $90 / 56 \mathrm{mmHg}$, with an HR of 125 beats/min. Her repeat cardiac markers were CK-MB, 2.64 $\mathrm{ng} / \mathrm{mL}$ and troponin-I, $0.017 \mathrm{ng} / \mathrm{mL}$, and her ABGAs showed a $\mathrm{pH}$ of 7.403; $\mathrm{PaO}_{2}, 83 \mathrm{mmHg} ; \mathrm{PaCO}_{2}, 52.8 \mathrm{mmHg}$; and $\mathrm{HCO}_{3}, 33.2 \mathrm{mEq} / \mathrm{L}$ with $95.9 \%$ oxygen saturation. Her ECG

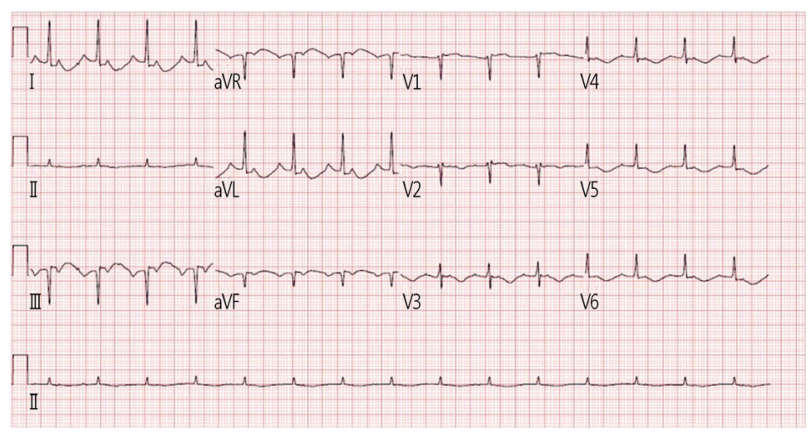

Fig. 4. Follow-up ECG demonstrating the PSVT conversion to a normal sinus rhythm. ECG, electrocardiogram; PSVT, paroxysmal supraventricular tachycardia.

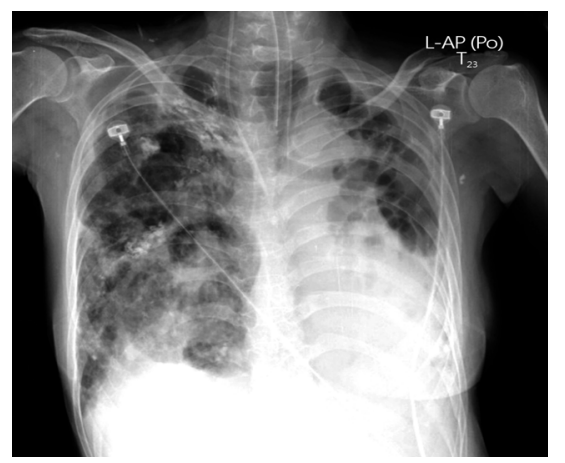

Fig. 5. Initial X-ray showing pneumonic consolidation with a tuberculous destroyed lung.

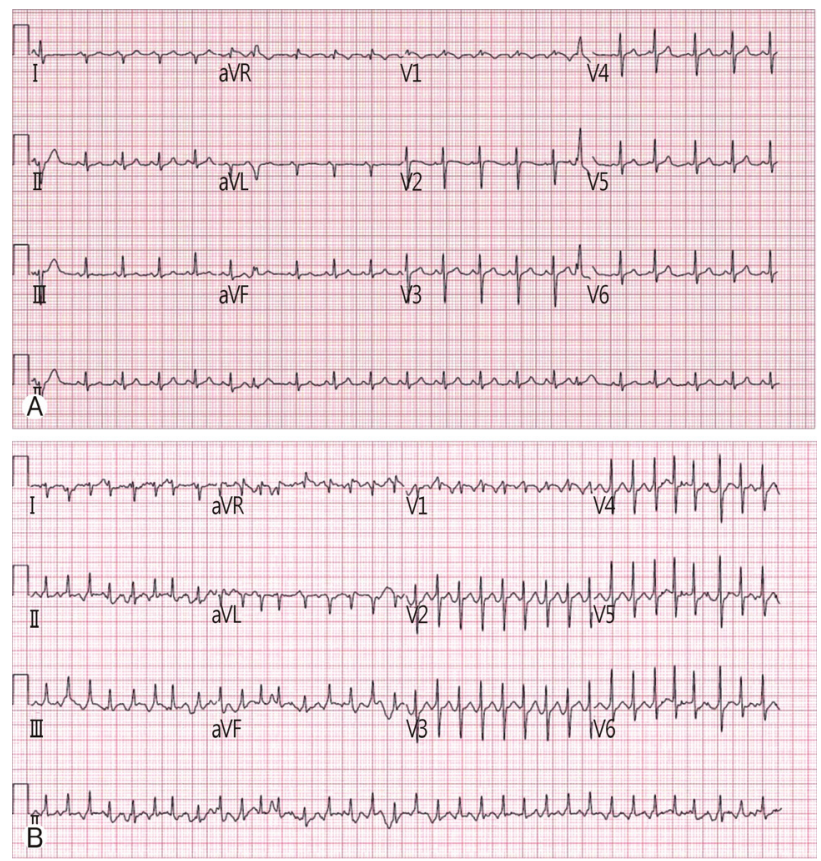

Fig. 6. (A) ECG showing a normal sinus rhythm. (B) ECG demonstrating PSVT. ECG, electrocardiogram; PSVT, paroxysmal supraventricular tachycardia.

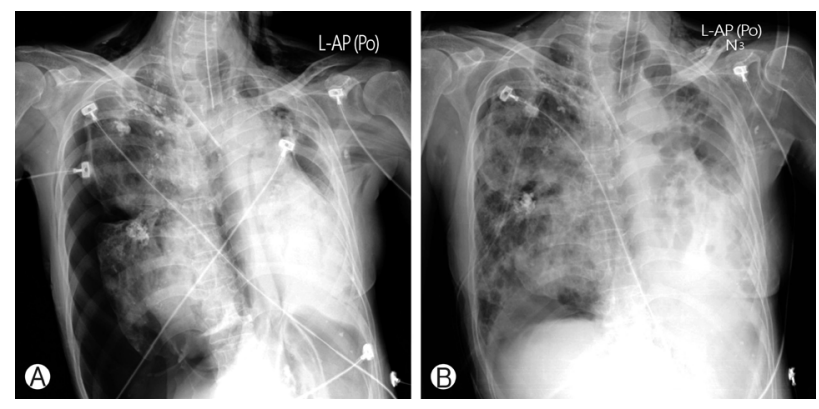

Fig. 7. (A) Chest X-ray showing a right-sided pneumothorax with subcutaneous emphysema. (B) Chest X-ray after chest tube placement showing resolution of the right-sided pneumothorax.

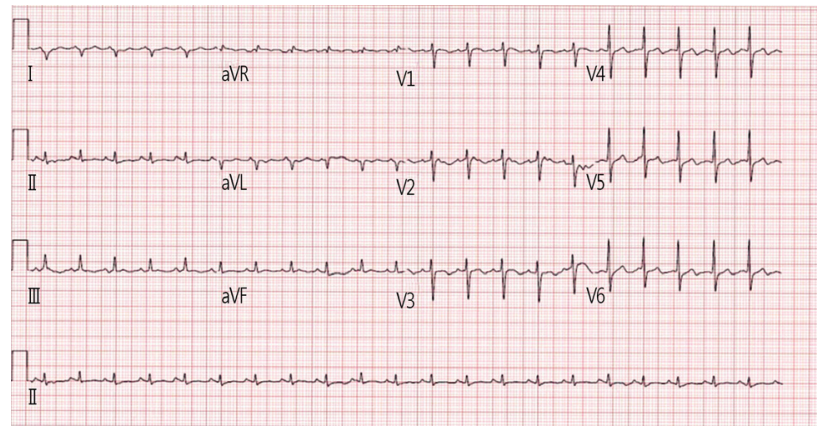

Fig. 8. Follow-up ECG demonstrating PSVT conversion to a normal sinus rhythm. ECG, electrocardiogram; PSVT, paroxysmal supraventricular tachycardia. 
showed conversion of her PSVT to the normal sinus rhythm (Fig. 8). Echocardiography showed a normally shaped left ventricle.

\section{DISCUSSION}

A pneumothorax remains one of the most serious complications of positive pressure ventilation [1]. It may be difficult to diagnose when its location is atypical or when the patient has an underlying cardiopulmonary disease or an altered mental status [4]. ICU clinicians are often presented with additional challenges in diagnosing a pneumothorax in patients with acute respiratory distress syndrome (ARDS).

Cardiac rotation, right ventricular dilatation, cardiac displacement, accumulation of air between the heart and the chest wall, and the effect of the pleural pressure on the coronary circulation have been suggested as the causes of electrocardiographic abnormalities [5-6]. Several electrocardiographic changes associated with a spontaneous or experimental pneumothorax have been described in literature [6-9]. Walston et al. [10], who studied 7 patients with a spontaneous left pneumothorax, described 4 relatively uniform ECG changes: a rightward shift in the mean frontal QRS axis, diminution of the precordial R-voltage, decreased QRS amplitude, and precordial T-wave inversion. Phasic electrocardiographic voltage alternations (electrical alternans) in patients with a left pneumothorax were described elsewhere [11,12]. There are few reports of ST-segment elevations or ECG changes suggestive of acute MI $[13,14]$, and these involved older patients with a tension pneumothorax and a previously known coronary heart disease. Only 1 case of ventricular tachycardia due to a pneumothorax has been reported [15].

In this paper, we report on 2 cases of a spontaneous pneumothorax presenting with PSVT by patients who required invasive mechanical ventilation due to acute respiratory failure. The etiology of a pneumothorax presented with PSVT is not completely known, but it may develop secondary to pulmonary arterial hypertension (PAH) by hypoxia. Arrhythmias are an increasingly common problem in patients with $\mathrm{PAH}$ due to the increased right heart pressure, the increased tricuspid regurgitation and the modulation of autonomic activity [16-18].

Although ECG is a readily available bedside test used to evaluate patients with chest pain, dyspnea, and hypotension before a chest X-ray, it is not considered the major test for the diagnosis of a pneumothorax. However, it can be a useful tool for recognizing a pneumothorax in the appropriate clinical setting where the initial diagnosis is not apparent from the medical history and the physical examination. It may be particularly useful for patients with ventilator support, as the pneumothorax could develop anterior to the lung and so may not be recognized on a supine chest X-ray. In patient-assisted ventilation with ARDS, careful attention to ECG changes may rapidly confirm a pneumothorax diagnosis.

\section{REFERENCES}

1. Strange C. Pleural complications in the intensive care unit. Clin Chest Med 1999;20:317-27.

2. Yarmus L, Feller-Kopman D. Pneumothorax in the critically ill patient. Chest 2012;141:1098-105.

3. No MY, Moon SH, Kim HS. Contralateral tension pneumothorax during one lung ventilation by a Univent tube. Yeungnam Univ J Med 2012;29:31-4.

4. Schramel FM, Golding RP, Haakman CD, Sutedja TG, de Jong KA, Postmus PE. Expiratory chest radiographs do not improve visibility of small apical pneumothoraces by enhanced contrast. Eur Respir J 1996;9:406-9.

5. Feldman T, January CT. ECG changes in pneumothorax. a unique finding and proposed mechanism. Chest 1984;86: 143-5.

6. Senthilkumaran S, Meenakshisundaram R, Michaels AD, Thirumalaikolundusubramanian P. Electrocardiographic changes in spontaneous pneumothorax. Int J Cardiol 2011;153: 78-80.

7. Krenke R, Nasilowski J, Przybylowski T, Chazan R. Electrocardiographic changes in patients with spontaneous pneumothorax. J Physiol Pharmacol 2008;59(Suppl 6):361-73.

8. Soltani P, Malozzi CM, Abi Saleh B, Omar B. Electrocardiogram manifestation of spontaneous pneumothorax. Am J Emerg Med 2009;27:750.e1-5.

9. Patanè S, Marte F, Genovese AM. Electrocardiographic presentation of spontaneous pneumothorax. Int J Cardiol 2013; 162:e62-3.

10. Walston A, Brewer DL, Kitchens CS, Krook JE. The electrocardiographic manifestations of spontaneous left pneumothorax. Ann Intern Med 1974;80:375-9.

11. Kuritzky P, Goldfarb AL. Unusual electrocardiographic changes in spontaneous pneumothorax. Chest 1976;70:535-7.

12. Kounis NG, Mallioris CN, Karavias D, Zavras G, Siablis D. Unusual electrocardiographic changes in intrathoracic conditions. Acta Cardiol 1987;42:179-85.

13. Diamond JR, Estes NM. ECG changes associated with iatrogenic left pneumothorax simulating anterior myocardial infarction. Am Heart J 1982;103:303-5.

14. Raev D. A case of spontaneous left-sided pneumothorax with 
ECG changes resembling acute myocardial infarction. Int J Cardiol 1996;56:197-9.

15. Forester D. Ventricular tachycardia with tension pneumothorax. JACEP 1979;8:340.

16. Wensel R, Jilek C, Dörr M, Francis DP, Stadler H, Lange $\mathrm{T}$, et al. Impaired cardiac autonomic control relates to disease severity in pulmonary hypertension. Eur Respir J 2009;34: 895-901.
17. Amar D, Roistacher N, Burt M, Reinsel RA, Ginsberg RJ, Wilson RS. Clinical and echocardiographic correlates of symptomatic tachydysrhythmias after noncardiac thoracic surgery. Chest 1995;108:349-54.

18. Song JH, Cheon SS, Bae MH, Lee JH, Yang DH, Park HS, et al. Cardiovascular beriberi: rare cause of reversible pulmonary hypertension. Yeungnam Univ J Med 2014;31:38-42. 